\title{
Analisis Pemilihan Jenis Tanaman dan Keamanan Pohon pada Lansekap Jalan Ruang Terbuka Hijau Tempat Pembuangan Akhir Sampah Piyungan Yogyakarta
}

\author{
Suparwoko \\ Program Studi Teknik Arsitektur Fakultas Teknik Sipil dan Perencanaan \\ Universitas Islam Indonesia \\ e-mail: andik_y@ftsp.uii.ac.id
}

\begin{abstract}
Abstrak
Makalah ini bertujuan untuk melakukan analisis pemilihan jenis tanaman dan rancangan keamanan pohon dari gangguan ternak pada lansekap jalan Ruang Terbuka Hijau (RTH) Tempat Pembuangan Akhir (TPA) Sampah di wilayah Kartomantul Daerah Istimewa Yogyakarta. Pemilihan jenis tanaman menjadi penting karena penentuannya sangat ditentukan oleh fungsi tanaman untuk mengurangi bau sampah, mereduksi polusi, dan bermanfaat bagi konservasi air, fungsi pengarah dan aspek keindahan. Masalah lain yang perlu diperhatikan adalah adanya ternak sapi yang setiap hari melewati jalan lingkungan TPA sampah Piyungan tersebut sehingga keberadaan pohon pada lansekap jalan lingkungan TPA menjadi terancam keamanannya, dimana daun pepohonan di lingkungan jalan di kawasan TPA sering dimakan oleh ternak sapi yang melewati jalan lingkungan TPA tersebut. Cara pemilihan jenis pohon untuk lansekap jalan di lingkungan TPA didasarkan atas aspek fungsi, manfaat dan keamanan pertumbuhan pohon di lingkungan TPA Piyungan. Pepohonnan lansekap jalur jalan menuju TPA sampah Piyungan akan dipilih dengan dasar fungsi tanaman pengarah dan keindahan. Untuk mengurangi bau sampah akan dipilih jenis pohon dengan kriteria pohon yang beraroma dan bermanfaat mengurangi polusi udara. Pada jalur menuju lokasi TPA digunakan jenis pohon pengarah seperti glodogan tiang, glodogan biasa dan pohon flamboyan, dsb. Karena pepohonan tersebut selain berfungsi sebagai pengarah dan fungsi keindahgan, maka pepohonan tersebut mampu menyerap polusi dan pepohonan tersebut juga berfungsi untuk mendukung keindahan lingkungan. Tanaman jenis perdu yang beraroma juga akan digunakan pada lansekap jalan lokasi TPA seperti tanaman kenangan, cempaka, mawar, serta melati dimana bau harup tanaman tersebut akan mempu mereduksi bau sampah di lingkungan TPA Piyungan. Tanaman peneduh, pengarah dan perdu di lingkungan TPA sampah Pitungan juga akan dikombinasi dengan tanaman lain yang berfungsi untuk mereduksi polusi udara seperti mahoni, angsana dsb.
\end{abstract}

Kata kunci: lansekap jalan, ruang terbuka hijau, jenis dan keamanan tanaman

\section{Pendahuluan}

Ruang terbuka hijau (RTH) sangat diperlukan diberbagai kawasan atau lingkungan perkotaan maupun perdesaan, namun RTH diperlukan pula di lingkungan tempat pembuangan akhir (TPA) sampah yang cukup luas. Karena TPA selain menghasilkan bau yang tidak sedap juga memberikan kesan kotor dan tidak indah atau kumuh. Sehingga penataan TPA perlu cara pemilihan tanaman yang berfungsi sebagai pereduksi bau dan mendukung aspek keindahan lingkungan alam.

Tempat Pembuangan Akhir sampah adalah tempat menimbun sampah dari beberapa tempat. Di TPA Piyungan juga melakukan daur ulang bagi sampah-sampah yang mungkin dapat di daur ulang, selain itu juga ada kegiatan pembuatan kompos. Sampah yang tidak dapat di daur ulang akan mengalami pembusukan dan menghasilkan gas metan yang berbahaya dan bau busuk. Keberadaaan 
TPA Piyungan memacu para pendatang untuk menjadi pemulung. Warga sekitar pun dengan keberadaan TPA mereka tidak repot mencari pakan ternak sapi. Dengan adanya TPA sapi-sapi dapat mencari makan dari sisa-sisa sampah dari pasar yang berupa sayuran dan buah-buahan. Perkembangbiakan sapi terjadi secara alami di TPA, sehingga penduduk sekitar dapat mempunyai puluhan sapi setiap orangnya.

Keberadaan sapi juga membuat bau busuk sampah menjadi tambah tidak sedap karena banyak kotoran sapi juga. Bau tidak sedap dan adanya kegiatan pengolahan sampah di TPA Piyungan mendorong untuk merencanakan TPA Piyungan menjadi tempat wisata belajar mengenai sampah dan di buat RTH untuk mengurangi polusi udara, tanah dan air. Dengan dibuatnya RTH diharapakan keadaan TPA menjadi lebih indah dan menarik untuk dikunjungi. Supaya Ruang terbuka Hijau (RTH) dapat berfungsi atau memberikan manfaat maka diperlukan pemilihan tanaman yang cocok untuk TPA Piyungan, yaitu untuk mengurangi polusi. Keberdaan sapi juga menjadi hal penting yang harus dipertimbangkan karena sifat sapi yang suka memakan dedaunan hijau tanaman dapat mengancam keamanan dari tanaman tersebut yang menjadi elemen dari RTH.

Permasalahan pada makalah ini adalah (1) pemilihan jenis tanaman yang cocok untuk di daerah yang sudah terkena polusi udara, bau sampah, dan tanah yang tercemar dan (2) Cara pengamanan tanaman dari hewan sapi yang mencari makan di TPA Piyungan. Sedangkan tujuan dari penulisan makalah adalah (1) Menganalisis jenis tanaman yang cocok untuk daerah TPA Piyungan yang tanah dan udaranya sudah terpolusi, dan (2) Menganalisis keamanan tanaman dari bahaya kerusakan yang disebabkan oleh hewan sapi. Adapun sasaran dalam penulisan ini adalah (1) Menemukan jenis tanaman yang cocok untuk daerah pembuangan kawasan TPA Piyungan, dan (2) Tanaman yang berada di kawasan TPA Piyungan dapat terlindungi dari ancaman kerusakan daun tanaman yang dimakan ternak sapi.

\section{Kondisi TPA Piyungan}

TPA-Piyungan berada di 16 km sebelah tenggara kota Yogyakarta 18 km dari Kabupaten Sleman dan 10,5 km dari Kabupaten Bantul, tepatnya di RT 04, Dukuh Bendo Ngablak dan RT 05 Dukuh Watu Gender, keduanya berada di Desa Sitimulya, Kecamatan Piyungan, Kabupaten Bantul. Sebagian lagi yang bagian selatan berada di Desa Bawuran, Kecamatan Pleret, Kabupaten Bantul (Anonim, 1995). Lokasi TPA ini merupakan daerah lembah pada perbukitan di Gunung Kidul.

Desa Sitimulya merupakan desa yang berada di dataran tinggi dengan ketinggian tanahnya 110 meter di atas permukaan air laut dengan suhu udara rata-rata $22^{\circ} \mathrm{C}-23{ }^{\circ} \mathrm{C}$, serta mempunyai curah 
hujan 23-600 mm/th (Setyawati, 2009). Keadaan wilayahnya curam dan mendatar membentuk ledok dengan jurang sedalam 40 meter serta tanahnya kering dan lapisan tanah subur sangat tipis sehingga kurang produktif.

Luas wilayah yang digunakan untuk tempat pembuangan kurang lebih 10 ha, dengan batas-batasnya adalah:

- Barat: Jalan lokal dan kebun/bukit

- Utara: Jalan lokal, kebun dan beberapa rumah

- Timur: Jalan lokal dan kebun/bukit

- Selatan: Jalan lokal dan kebun/bukit

Kecepatan angin yang bertiup dari barat daya dan pada bulan Mei dan September angin bertiup dari arah timur dan Selatan dengan kecepatan rata-rata berkisar 10-20 m/det. Di sekitar TPA sudah terjangkau listrik dengan kapsaitas 220 volt dengan daya sebesar 1300 watt. Listrik digunakan untuk operasional kantor dan TPA, selain itu juga terdapat genset sebagai cadangan ntuk aerator pengolahan lindi. Lingkungan wilayah TPA terdapat hutan dengan bukit-bukit, sawah dan tegalan yang berada di saluran irigasi. Permukiman terdekat berada di sebelah utara TPA. Badan air yang terdekat dengan lokasi TPA adalah saluran alami yang awalnya mengalirkan limpasan air hujan di lokasi TPA dan sekitarnya, saluran ini mengalir ke sungai Opak yang berjarak 1,5 km sebelah barat laut.Masyarakat sekitar TPA Piyungan mepunyai latar belang lulusan SD dan sebagian kecil SLTA, mereka bermata pencaharian sebagai pemulung, petani dan ternak sapi. Sapi yang mereka milik bisa mencapai puluhan ekor untuk satu orang, mereka tidak merasa kewalahan dalam memeberi makan ternaknya karena sapi mereka mencari makan di TPA yang zona aktif, sehingga saat siang hari TPA terdapat ratusan ekor sapi yang sedang mencari makan.
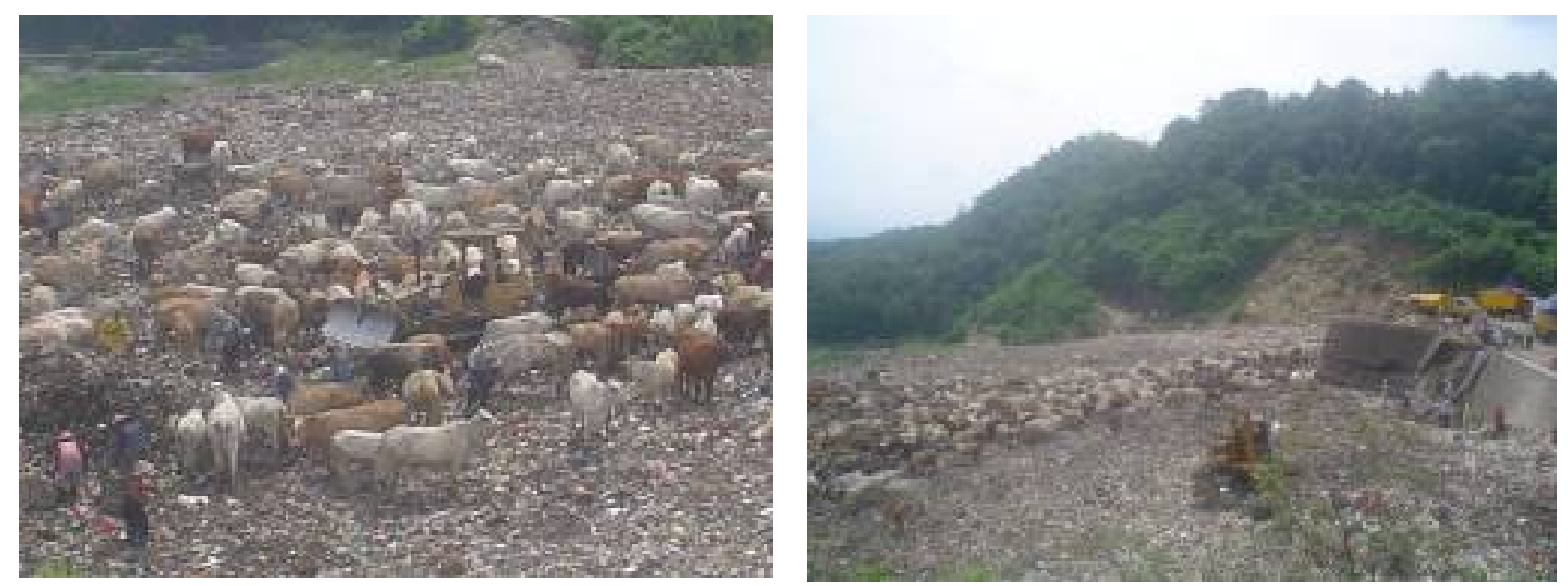

Gambar 1. Hewan Sapi yang sedang mencari makan di TPA Piyungan 


\section{Elemen Ruang Terbuka dan Lansekap Jalan}

Ruang terbuka hijau terbentuk dari kumpulan beberapa vegetasi. Banyak jenis tanaman yang dikelompokan sesuai bentuk dan fungsinya (Direktorat Bina Marga, 1996). Persyaratan untuk menanam tanaman di suatu daerah antara lain:

a. Disenangi dan tidak berbahaya bagi warganya

b. Mampu tumbuh di lingkungan yang marjinal

c. Tahan terhadap gangguan fisik

d. Perakaran dalam sehingga tidak mudah tumbang

e. Cepat tumbuh, bernilai hias dan arsitektural

f. Dapat Menghasilkan O2 dan meningkatkan kualitas lingkungan

g. Bibit mudah di dapat engan harga yang murah / terjangkau oleh masyarakat

h. Prioritas menggunakan vegetasi local

i. Keanekaragaman hayati.

Berbagai jenis tanaman dengan bentuk, struktur dan warna yang berbeda. Beberapa macam tanaman yang dikelompokan sebagai berikut:

Keberadaan RTH memiliki fungsi ekologis, sosial, ekonomi, dan arsitektural dan memiliki nilai estetika yang dimilikinya (obyek dan lingkungan) tidak hanya dapat dalam meningkatkan kualitas lingkungan dan untuk kelangsungan kehidupan kawasan tetapi juga dapat menjadi nilai kebanggaan dan identitas kawasan (Laboratorium Perencanaan Lanskap, 2005). Pengaturan pada lansekap jalan (Direktorat Bina Marga, 1996) dapat dilakukan dengan catatan sebagai berikut:

a. Pengaturan penanaman pada jalur tepi jalan sebaiknya jalur tanaman diletakan di antara jalur pejalan kaki dan jalur kendaraan. Penentuan jenis tanman sisesuaikan dengan lebar jalur tanaman.

b. Untuk median jalan harus memenuhi lebar minimum 0.80 meter sedangkan lebar ideal adalah 4.00-6.00 meter. Jenis tanaman harus disesuaikan dengan bentuk yang ditinggikan atau yang diturunkan dan apakah di persimpangan atau di daerah bukaan.

c. Pada daerah tikungan ada beberapa yang harus diperhatikan yaitu:

1) jarak pandang henti

2) panjang tikungan

3) ruang bebas samping di tikungan

4) tanaman sebaiknya perdu dengan tinggi maximal 0.80 meter dan berwarna.

5) Tanaman sebaiknya diletakan di ujung tikungan 
Pada daerah persimpangan harus ada derah bebas pandangan agar pengemudi tidak terhalang pandangnnya dan pemilihan jenis tanaman harus memperhatikan bentuk persimpangan apakah sebidang atau tidak sebidang (Departemen Pekerjaan Umum 1996). Pemilihan jenis tanaman untuk lansekap jalan sebaiknya:
a. perakaran tidak merusak konstruksi jalan
b. mudah dalam perawatan
c. batang/percabangan tidak mudah patah
d. daun tidak mudah rontok/gugur.

\section{Tanaman Sebagai Pengarah Pandangan}
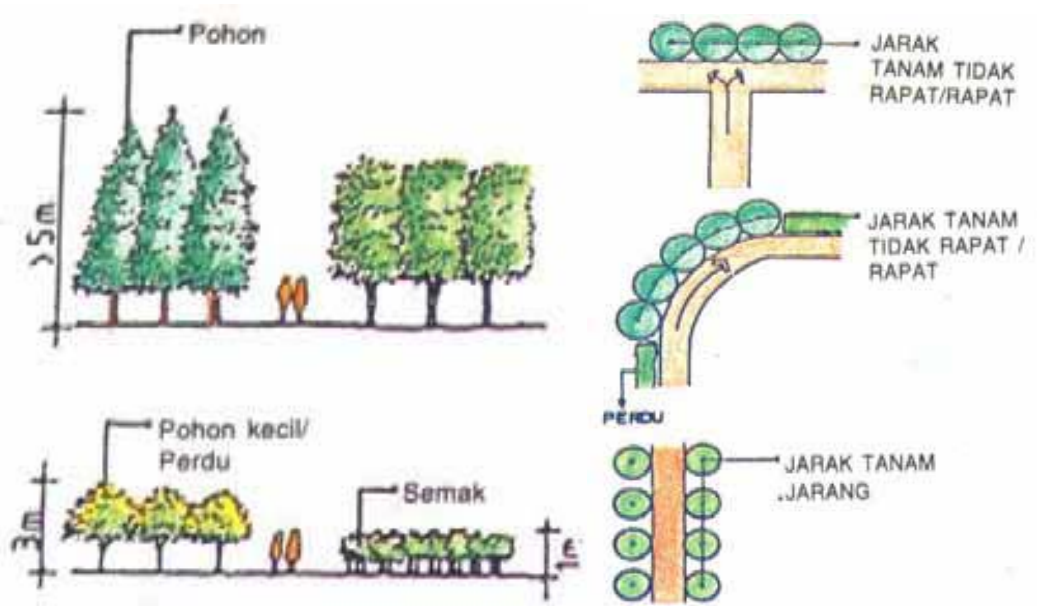

- Tanaman perdu atau pohon ketinggian $>2 \mathrm{~m}$

- Ditanam secara massal atau berbaris.

- Jarak tanam rapat.

- Untuk tanaman perdu/semak digunakan

- tanaman yang memiliki warna daun hijau muda

- agar dapat dilihat pada malam hari.

Gambar 2. Vegetasi Pengarah Pandangan (Sumber: Departemen Pekerjaan Umum, 1996)

Sejumlah tipologi lansekap jalan dapat dilihat pada Gambar 3 dan Gambar 4.
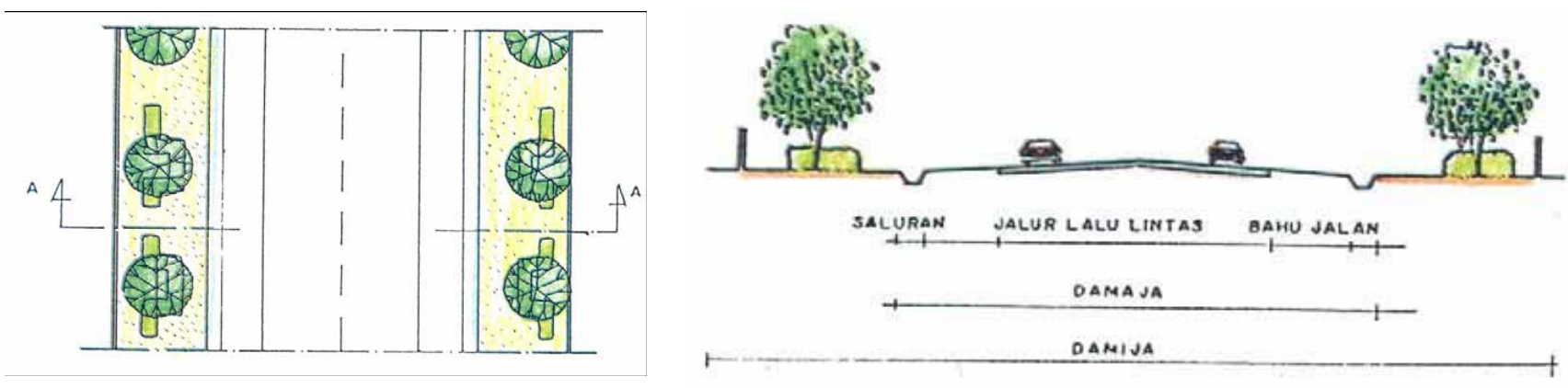

Gambar 3. Lansekap Jalan Tanpa Lereng 


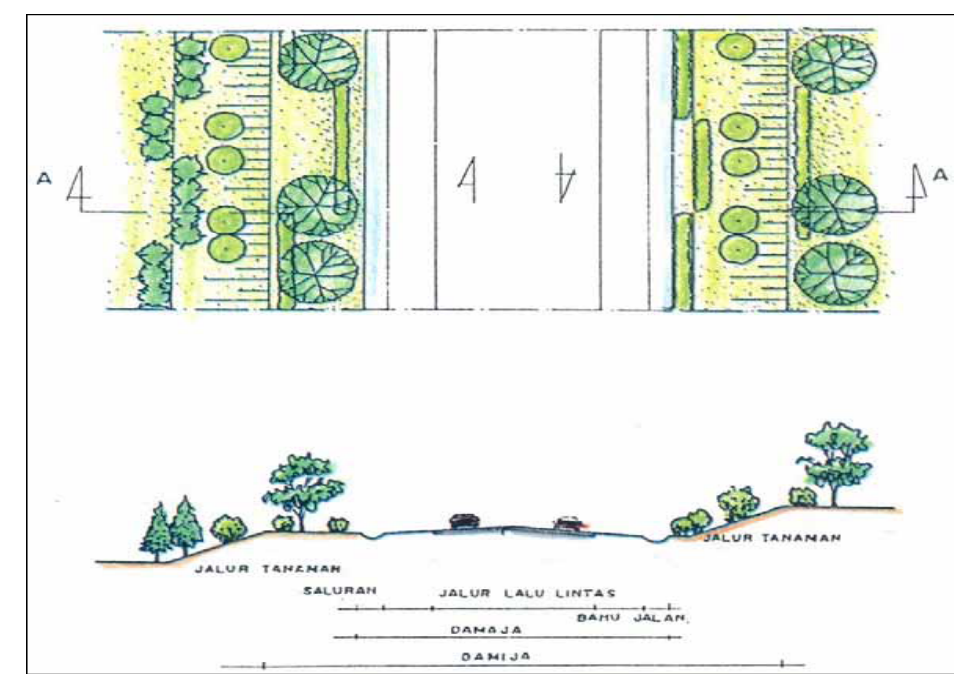

Gambar 4. Lansekap Jalan Dengan Lereng (Sumber: Departemen Pekerjaan Umum, 1996)

Secara arsitektural RTH dapat meningkatkan nilai keindahan dan kenyamanan kota melalui keberadaan taman-taman kota, kebun-kebun bunga, dan jalur-jalur hijau pada lansekap jalan (Surkawi, ). RTH dibangun dari kumpulan tumbuhan dan tanaman atau vegetasi yang telah diseleksi dan disesuaikan dengan lokasi serta rencana dan rancangan peruntukkannya. Lokasi yang berbeda (seperti pesisir, pusat kota, kawasan industri, sempadan badan-badan air, dll) akan memiliki permasalahan yang juga berbeda yang selanjutnya berkonsekuensi pada rencana dan rancangan RTH yang berbeda (Laboratorium Perencanaan Lanskap, 2005). Dalam konteks ini, linkungan studi kasus untuk perencanaan RTH adalah di lingkungan TPA yang memiliki spesifik masalah bau sampah, polusi udara, kumuh, kotor dan masalah ternak sapi yang memakan dedaunan lansekap jalan di lingkungan TPA.

\section{Ternak Sapi}

Pemeliharaan sapi potong mencakup penyediaan pakan (ransum) dan pengelolaan kandang. Fungsi kandang dalam pemeliharaan sapi adalah (Bos, 2010):

a. Melindungi sapi dari hujan dan panas matahari

b. Mempermudah perawatan dan pemantauan

c. Menjaga keamanan dan kesehatan sapi

Pakan merupakan sumber energi utama untuk pertumbuhan dan pembangkit tenaga. Makin baik mutu dan jumlah pakan yang diberikan, makin besar tenaga yang ditimbulkan dan masih besar pula energi yang tersimpan dalam bentuk daging (Bos Sp, 2010). Pemberian Ppakan sapi dapat dengan 3 cara yaitu pengembalaan, jatah atau keraman dan kombinasi keduanya. Pada umumnya sapi membutuhkan pakan berupa hijauan segar, hijauan keri dan silase. Hijauan berupa jerami, rumput, daun lamtoro dll. Tetapi sapi juga butuh tambahan (comboran) yaitu berupa probiotik MiG Ternak/migro SUPLEMEN 2 kali sehari. dan tambahan Pada umumnya, setiap sapi membutuhkan 
makanan berupa hijauan. Sapi dalam masa pertumbuhan, sedang menyusui, dan supaya tidak jenuh memerlukan pakan yang memadai dari segi kualitas maupun kuantitasnya. Pemberian pakan dapat dilakukan dengan 3 cara: yaitu penggembalaan (Pasture fattening), kereman (dry lot faatening).

\section{Metode Penelitian}

Secara umum penelitian yang dilakukan adalah penelitian lapangan dengan melakukan trial pada salah satu unit filter. Trial dilakukan dengan mengganti sistem backwash pada salah satu dari tiga unit filtrasi. Dengan trial ini, air untuk backwash diganti dengan menggunakan air yang berasal dari aerasi (tanpa klorin) dengan tujuan agar mikroorganisme yang terdapat pada media.

Pengambilan sampel dilakukan pada 5 titik yaitu: 1 sampel air sebelum filtrasi, 3 sampel air setelah filtrasi, dan 1 sampel untuk air yang telah siap didistribusikan. Pemeriksaan kualitas air dilakukan secara in situ (di lapangan) dan di laboratorium. Pemeriksaan di lapangan meliputi pengukuran suhu, $\mathrm{pH}$, oksigen terlarut dilakukan bersamaan dengan pengambilan sampel. Pemeriksaan di laboratorium meliputi parameter Fe dan Mn, dilakukan di Laboratorium Kualitas Air, Jurusan Teknik Lingkungan FTSP UII dengan prosedur uji SNI 06-6989.4-2004 untuk Fe dan dan SNI 066989.5-2004 untuk Mn. Untuk mengetahui efisiensi pengolahan maka dilakukan analisis data dari hasil uji laboratorium. Pada unit filtrasi ini dilakukan dengan membandingkan antara kualitas influent filter dan effluent filter. Diagram alir penelitian disajikan pada Gambar 5, sedangkan lokasi pengambilan sampel ditunjukkan pada Gambar 6.

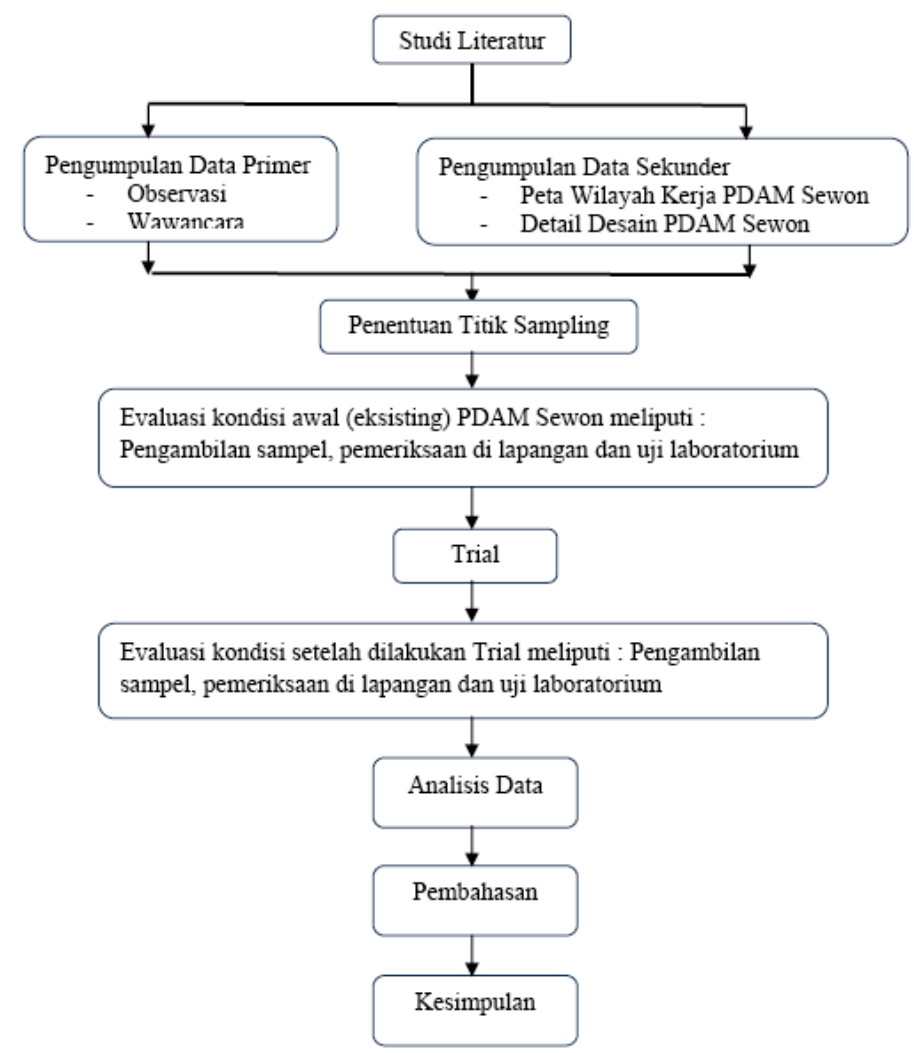

Gambar 5. Diagram Alir Metode Penelitian 


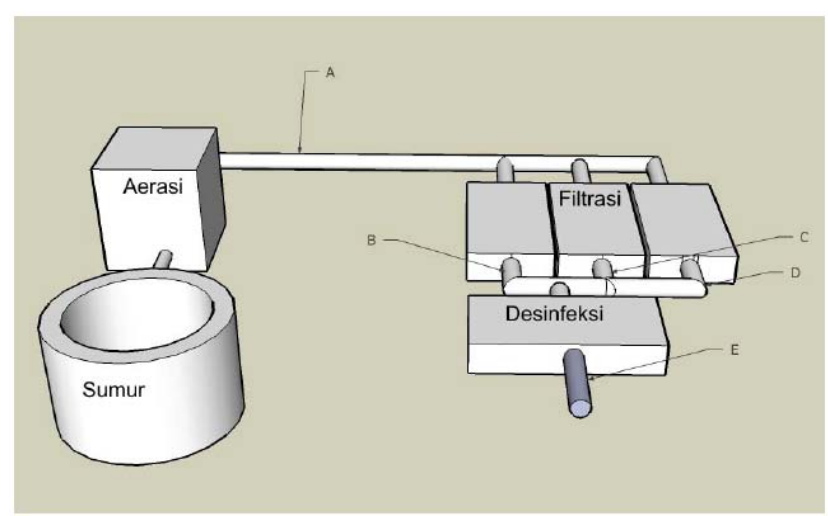

Gambar 6. Titik Pengambilan Sampel

\section{Hasil dan Pembahasan}

\section{Analisis Pemilihan Tanaman}

Keberadaaan masyarakat di daerah TPA Piyungan rentan terkena penyakit pernafasan dan kulit karena merupakan daerah yang kotor dan sudah terkena polusi karena timbunan sampah. Timbunan samapah menimbulkan bau yang menyengat karena adanya gas metana akibat pembusukan sampah, gasa metan ini lebih berbahaya dari gas CO2 (Anonim, 2010; Direktorat Binamarga, 1996; Mentri Kehutanan. 2004).

Bau sampah ini sangat mengganggu kenyamanan sehingga dibutuhkan filtrasi udara sehingga bau sampah tidak begitu menyengat saat udara memasuki rumah-rumah warga. Filtrasi udara dapat memanfaatkan vegetasi pohon dan perdu yang berfungsi sebagai reduktor polutan dan vegetasi yang beraroma. Vegetasi atau pohon yang bearoma dan sekaligus reduktor polutan adalaha pohon Cempaka (Nurshendi, 2004). Pohon cempaka termasuk pohon besar dan mudah di dapat sedangkan perdu yang cocok untuk ditanami di sekitar fasilitas penunjang TPA adalah Melati dan Mawar karena perdu ini mengeluarkan aroma harum. Sebagai vegetasi tambahan dan sudah ada di TPA Piyungan adalah pohon Angsana, pohon ini berfungsi sebagai reduktor polutan dan juga bermanfaat untuk warga sekitar karena jika sudah tua batang pohon ini dapat dimanfaatkan sebagai furniture.

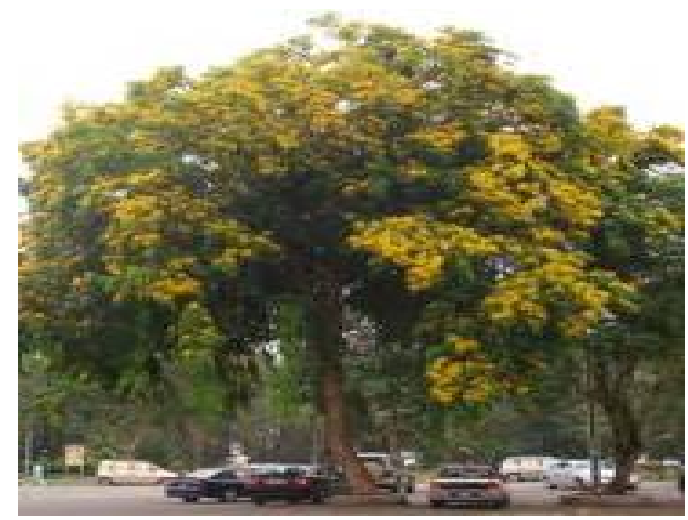

Gambar 7. Pohon Cempaka (Michelia champaca)

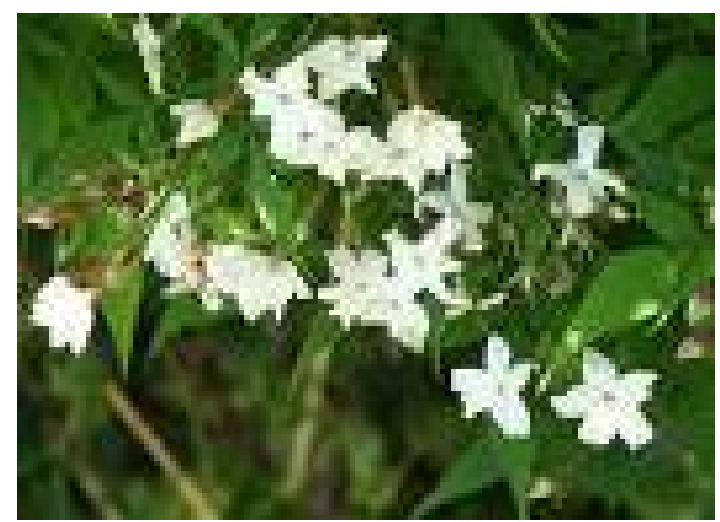

Gambar 8. Foto tanaman Melati (Jasminum sambac). 
Keberadaan TPA membuat daerah tesebut teerkesan kumuh dan kotor krena banyak timbunan sampah. Untuk memperindah dan memberikan suasan yang sejuk bagi daerah dan kawasan TPA di beri Vegetasi yang berbunga indah dan bertajuk indah seperti Pohon Glodogan Tiang yang mempunyai tajuk Indah dan perdu bunga Sepatu di bagian depan gerbang utama dan gerbang masuk TPA. Sebagai kombinasi di tanami pohon palem sebagai pengara dan pohon palem adlah eksisting.

\section{Analisis Keamanan Tanaman}

Keberadaan sapi yang mencari makan setiap hari datang ke TPA tanpa di giring pemiliknya tetapi mereka berdatangan secara berkelompok (sekeluarga) ini sangat mengherankan karena mereka akan kembali lagi ke kandangnya sendiri tanpa digiring juga. Sapi-sapi ini makan di TPA dan kawin serta beranak pun di zona TPA ini terjadi secara alami. Tetapi keberadaan sapi ini membahayakan tanaman sekitar TPA karena mereka akan merusak tanman dan memakan dedaunanya. Keamanan vegetasi di pinggir jalan operasional TPA Piyungan sangat riskan rusak karena keberadaan sapi yang suka merusak tanaman dan memakan dedaunanya (Bos, 2010). Untuk itu teknis penanamannya yaitu dengan sistem urug tanah dengan tanah yang subur setinggi 1,5 meter atau lebih dan sebagian yang lain menggunakan bus beton yang disusun ke atas dengan posisi tanaman di tengah bus beton sehingga sapi tidak bisa menjangkau dedaunan pohon yang ada di lansekap jalan.

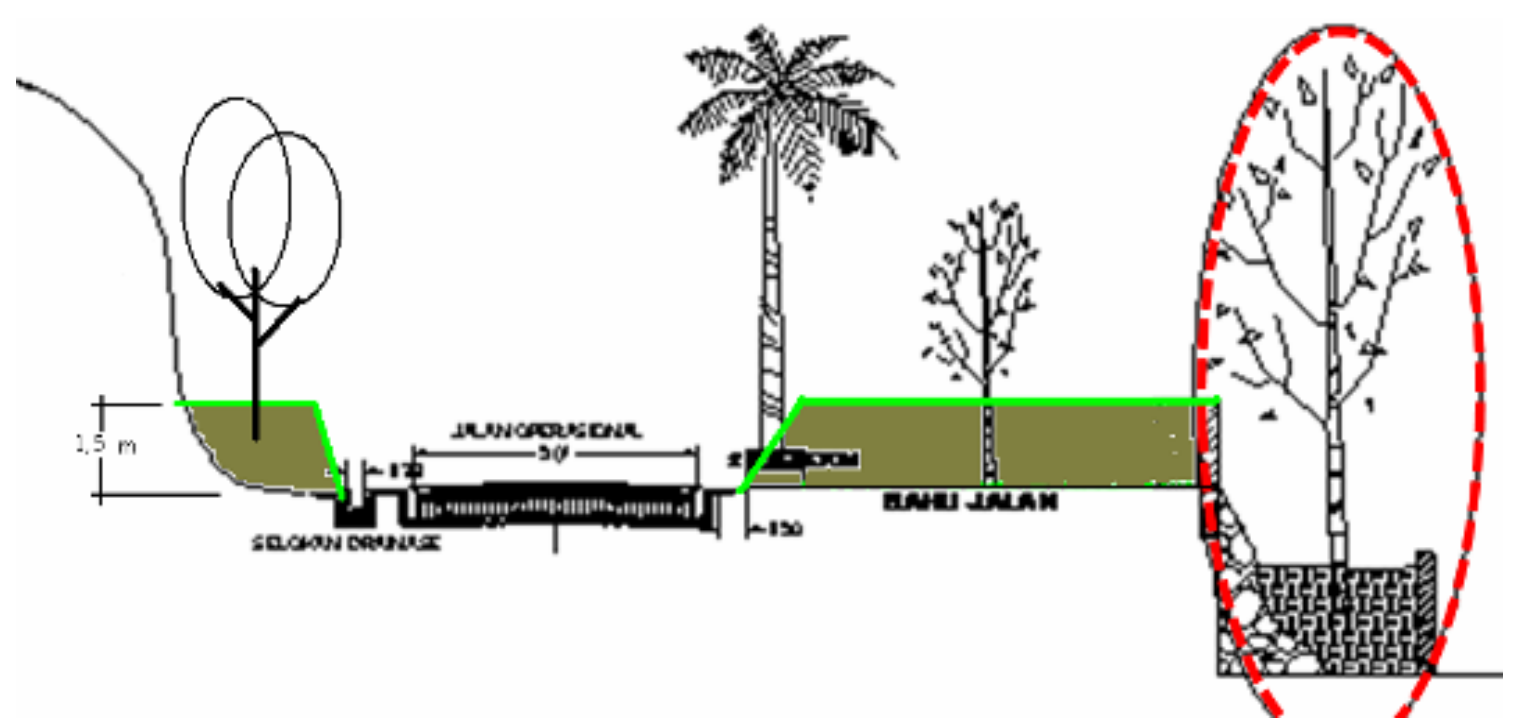

Gambar 9. Peninggian tanah pada pinggiran zona pembuangan sampah untuk dasar tanaman setinggi 1,5 meter agar sapi tidak bisa masuk pada area tanaman. 


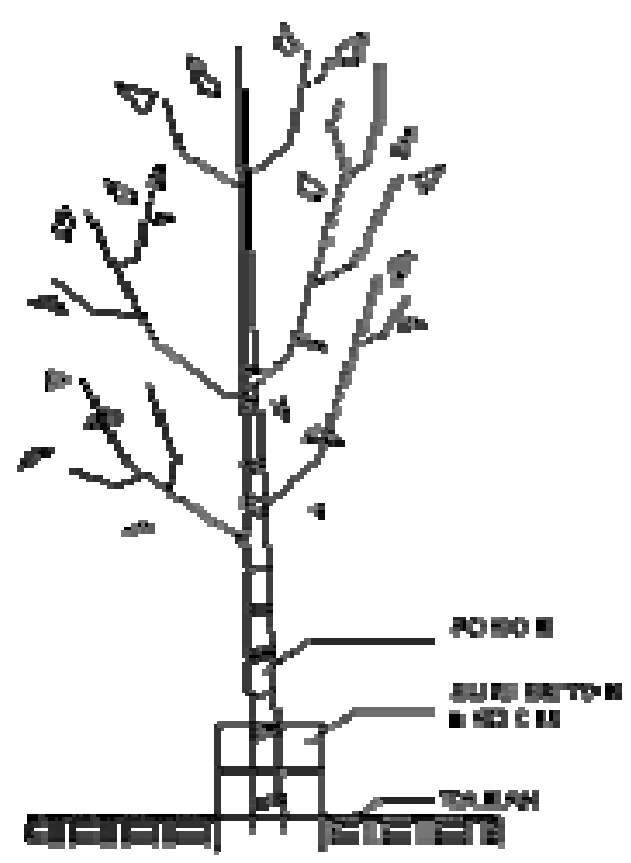

Gambar 10. Cara penanaman pohon (Hasfram Dian Konsultan, 1995)

Setelah pohon untuk RTH Piyungan terpilih, maka penanaman disesuaikan dengan letak masalah yang berkaitan dengan 1) fungsi lansekap jalan untuk aspek pengarah dan keindahan, dan 2) manfaat tanaman pereduksi polusi udara dan bau sampah, serta 3) perlindungan tanaman dari jangkau ternak sapi. Mengenai jarak tanam dan ukuran media tanam didasarkan pada standar rancangan letak, ukuran dan jarak tanam yang ada pada gambar dan rancangan tersaji pada makalah ini dan dari sumber Direktorat Jenderal Bina Marga tahun 1996 dengan judul buku Tata Cara Perencanaan Teknik Lansekap Jalan.

\section{Kesimpulan dan Saran}

\section{Kesimpulan}

1. Secara umum kinerja unit filtrasi PDAM unit Sewon dalam menurunkan kadar besi (Fe) cukup baik. Kadar Fe telah memenuhi Baku Mutu Kepmenkes No. 907 Tahun 2002, kecuali pada pengukuran bulan april dan mei yang melebihi $0.3 \mathrm{mg} / \mathrm{l}$. Sedangkan dalam menurunkan kadar mangan, performance unit filter kurang optimal dan tidak memenuhi baku mutu yang ditetapkan. Hal ini disebabkan karena operasional filter tersebut dan faktor kondisi lingkungan yang kurang mendukung.

2. Penggantian sistem backwash dengan menggunakan air baku bertujuan untuk mengoptimalkan kinerja filter dengan memanfaatkan prinsip kerja mikroorganisme. Namun penggantian sistem backwash jika tidak didukung oleh operasional yang benar, kondisi lingkungan, dan juga 
penggunaan media filter yang tidak seragam, maka menghasilkan kinerja filter yang juga tidak optimal. Hal ini dapat dilihat pada ketiga unit filter yang secara umum menunjukkan kinerja pengolahan yang sama.

\section{Saran}

1. Pemantauan dalam pengoperasian dan pemeliharaan yang teratur merupakan bagian penting dalam menentukan kinerja unit pengolahan air minum.

2. Perlu dilakukan penggantian media filter dilihat dari hasil lengkung ayakan yang menunjukkan bahwa media filter yang digunakan tidak seragam.

3. Unit filter pada PDAM unit Sewon ini merupakan jenis rapid sand filter sehingga untuk menerapkan prinsip kinerja mikroorganisme akan cukup sulit karena laju filtrasi yang tinggi. Untuk itu laju filtrasi perlu diperlambat antara lain dengan cara mengurangi debit air yang masuk atau mempeluas dimensi filter.

4. Frekuensi sampling sebaiknya ditingkatkan agar dapat diketahui lebih jelas fluktuasi pada unit filter.

\section{Daftar Pustaka}

Anonim. Bab II: Penyediaan RTH di Kawasan Perkotaan, diakses tanggal 28 Agustus 2010 dari http://www.penataanruang.net/taru/upload/nspk/pedoman/RTH/7.Bab2.pdf

Anonim. Bab VIII: Vegetasi Pada Ruang Terbuka Hijau, diakses pada tanggal 27 Agustus 2010 dari http://teknik.ums.ac.id/kuliah/ruhiko/file/A5-PDFFINAL\%20buku\%20teks\%20ruhiko\%20DIM/Fin\%20A5-bab\%208\%20vegetasi\%20ars25\%20sept.pdf

Anonim. Bab III: Pemanfaatan RTH di Kawasan Perkotaan, diakses tanggal 17 September 2010 dari: http://penataanruang.pu.go.id/taru/upload/nspk/pedoman/RTH/8.Bab3.pdf

Bos Sp. (2007). Budidaya Ternak Sapi, diakses pada tanggal 27 November 2010 dari http://www.pdftop.com/view/aHR0cDovL21pZ3JvcGx1cy5jb20vYnJvc3VyL0J1ZGlkYXlhJ TIwc2FwaSUyMHBvdG9uZy5wZGY=

Departemen Pekerjaan Umum. (1996). Ruang Terbuka Hijau Wilayah Perkotaan. Makalah disampaikan pada lokakarya Pengembangan Sistem RTH di Perkotaan. Dalam rangkaian Hari Bakti Pekerjaan Umum ke 60. Lab. Perencanaan Lanskap Departemen Arsitektur Lanskap Fakultas Pertanian - IPB. Makalah Lokakarya PENGEMBANGAN SISTEM RTH DI PERKOTAAN Dalam rangkaian acara Hari Bakti Pekerjaan Umum ke 60 Direktorat Jenderal Penataan Ruang Departemen Pekerjaan Umum.

Direktorat Jenderal Bina Marga. (1996). Tata Cara Perencanaan Teknik Lansekap Jalan. Jakarta: Departemen Pekerjaan Umum. 
Hakim, Rustam \& Utomo, Hardi. (2003). Komponen Perncangan Arsitektur Lansekap: PrinsipUnsur dan Aplikasi Desain. Jakarta: Bumi Aksara.

Hasfarm Dian Konsultan Indonesia. (1995). Manual Operasi dan Pemeliharaan TPA Piyungan. Yogyakarta: Yogyakarta Urban Development Project.

Laboratorium Perencanaan Lanskap. (2005). Ruang Terbuka Hijau (Rth) Wilayah Perkotaan, Bogor: Departemen Arsitektur Lanskap, Fakultas Pertanian - IPB.

Mentri Kehutanan. (2004). Pedoman Pembuatan Tanaman Penghijauan Kota Gerakan Nasional Rehabilitasi Hutan dan Lahan. Mentri Kehutanan.

Nurshendi, Saptoto. (2004). Pengelolaan Kapasitas Tempat Pembuangan Akhir Sampah. Skripsi, tidak dipublikasikan. Yogyakarta: Universitas Muhammadiyah Yogyakarta.

Surkawi, _ _ Kuantitas dan Kualitas Ruang Terbuka Hijau (RTH) di permukiman Kota. 